\title{
Phase Transformations, Microstructure and Shape Memory Effect of NiTiAg Alloy with Different Atomic Percentages (at. $\%$ Ag) Manufactured by Casting Method
}

\author{
Saja M. Hussein ${ }^{a *}$, Khansaa D. Salman (D) b, Ahmed A. Hussein ${ }^{c}$ \\ a Department of Electromechanical Engineering, University of Technology, Baghdad, Iraq, \\ 50748@student.uotechnology.edu.iq \\ b Department of Electromechanical Engineering, University of Technology, Baghdad, Iraq, \\ drkhansaa_ds@yahoo.com \\ c Department of Electromechanical Engineering, University of Technology, Baghdad, Iraq, \\ ahmedabdulqaderhussein@gmail.com
}

Submitted: $13 / 09 / 2020$

K E Y W O R D S

Cast method, DSC, NiTiAg, SMAs, SME, VAR.
Accepted:26/10/2020

Published: 25/04/2021

\section{A B S T R A C T}

In this paper, shape memory alloys (SMAs) (NiTi-based) have been manufactured by casting with a different atomic percentage of a silver element (0, 1, 2 and 3 at. \% Ag) using a Vacuum Arc Remelting (VAR) furnace. The silver element is added to the binary alloys due to its excellent properties such as (anti-corrosion, anti-bacterial and high electrical conductivity), which make these alloys using in wider applications. These alloys with different atomic percentages (Ni55Ti45 Ag0, Ni55Ti44Agl, Ni55Ti43 Ag2 and Ni55Ti42 Ag3) have been manufactured. The successful manufacturing process has been achieved and proved via examinations and tests. The FESEM microscopic examinations show that the silver element has been distributed uniformly and homogeneously in the NiTi matrix. Moreover, the emergence of austenite phase, martensite phase and little amount impurities. Regarding the XRD examination, showed that there is an increase in the number of peaks of Ag phase with an increase in the atomic percentage of the silver element, as well to emergence of phase (Ti2Ni) upon heating, phase (Ti 002) upon cooling, and phase (Ni4Ti3) is not desired. The starting and finishing of the phase transformations have been determined for all samples by the DSC test. The Shape Memory Effect (SME) for the alloy (Ni50Ti42Ag3) is measured to be about $89.99 \%$.

How to cite this article: S. M. Hussein, K. D., Salman, and A. A. Hussein, "Phase transformations and physical properties of NiTiAg alloy with different at omic percentages (at. \% Ag) manufactured by casting method," Engineering and T echnology Journal, Vol. 39, Part A, No. 04, pp. 543-551, 2021.

DOI: https://doi.org/10.30684/etj.v39i4A.1833

This is an open access article under the CC BY 4.0 license $\underline{\text { http: //creativecommons.org/licenses/by/4.0 }}$ 


\section{INTRODUCTION}

Shape memory alloys (SMAs) are metallic materials (smart materials) that respond to external changes such as temperature and mechanical load, thus producing deformation (generally 2-10\%). These materials are described as natural thermo-mechanical actuators that are capable of carrying out several mechanical works [1]. SMAs can even remember their predefined shape after the deformations during the heating process. Nitinol can be martensite phase (B19), austenite phase (B2), or a combination of both phases, depending on the temperature. SMAs usually are transformed between the low-temperature phase called the martensite phase and the high-temperature phase called the austenite phase. Several factors can influence the phase transformations of shape memory alloys such as processing techniques, variation in nickel content, thermal cycling, combination thermomechanical treatment and ternary alloying elements [2]. SMAs (NiTi) that were first produced in 1960 are known for two unique properties; superelastic effect (SE), and shape memory effect (SME), mechanically or thermally activated $[3,4]$. NiTi alloy has an excellent shape memory effect property. It is called thermal shape memory alloy because it bends and expands upon cooling, and then returns to its size and shape at a certain temperature, this feature is important for many alloy devices such as (NiTi) [5]. In addition, there are several properties for this alloy such as (corrosion resistance, biocompatibility). This indicates that shape memory alloy (NiTi) has an important role in many important applications such as medical and engineering applications [6].

SMAs (NiTi-based) have been developed depending on application requirements by adding a new element to these binary alloys. Additives have an important role in controlling phase transformation, crystal structure and hysteresis loop widths [7-9]. Such additions that lower the transformation temperatures are $(\mathrm{Fe}, \mathrm{Mn}, \mathrm{Cr}, \mathrm{V}, \mathrm{Al})$, while those increase the transformation temperatures are $(\mathrm{Au}, \mathrm{Pt}, \mathrm{Pd}, \mathrm{Zr}, \mathrm{Hf})$. The addition of $(\mathrm{Nb}$ and $\mathrm{Fe})$ widens the transformation hysteresis whereas $(\mathrm{Cu})$ narrows it. Moreover, these additions have a great influence on mechanical and functional properties [10]. Silver is a promising element because it has important properties and advantages such as (good antibacterial ability, excellent biocompatibility, and thermal stability), in addition to excellent corrosion resistance due to the creation of a layer of oxidation [11,12]. Adding a silver element to alloys NiTi-based has been presented in [13]. For the first time, the silver element was introduced in the year (1991) using Electron Beam Melting (EBM) technique. The results of this study showed that it is difficult to add silver to the binary alloy due to the high vapor pressure of silver. A vacuum arc remelting (VAR) furnace was used to produce an alloy (NiTiAg) $[14,15]$. These studies reported the difficulty of silver element melting due to the high pressure of steam of (Ag). But these studies showed that alloy NiTiAg has strength higher than NiTi as well as improved corrosion rate and biocompatibility. Adding a silver element to the binary alloys NiTi using (VAR) method has been presented in [16]. The results of this approach showed that the prepared alloys are homogeneous and stable. While the silver element was lost with repeated melting due to the high steam pressure. This study showed that the silver element is anti-bacterial (increases the anti-bacterial activity of the alloy NiTi), and rate recovery for alloys manufactured was (72-85\%).

The problem of research in the process of manufacturing an alloy (NiTi) with the addition of silver, due to the difficulty of distributing the silver element inside the alloy, as the manufacturing process affects the properties of the produced alloy. In general, there are two main methods of manufacturing SMAs, which are powder metallurgy and casting method. The first method (PM) is not used because in this research an ingot is produced $[1,17]$. The second method in which the used materials must be of high purity because the purity of the materials affects the homogeneity and thus if the materials are not pure it affects the chemical composition as well as the biological properties. In general, the casting method is classified as Electron Beam Melting (EBM), Vacuum Induction Melting (VIM) and Vacuum Arc Remelting (VAR) [18].

Vacuum Arc Remelting (VAR) does not contain a crucible of graphite, which leads to the production of high-purity alloys (low carbon content) [19], while (VIM) requires a crucible of graphite, which causes impurities in the produced alloys (such as carbon element) and thus the alloy is not of high purity [17]. (EBM) produces high-purity alloys, but during the manufacturing process, some elements evaporate, which leads to a high vacuum pressure during melting $[1,20]$. The aim of the present research is to produce a homogeneous alloy with different percentages by using a (VAR) furnace and to study the microstructure, phase transformations. 
The rest of the sections of this research consist of the following. The second section consists of the materials used, the manufacturing process and subsequent processes. The third section consists of the results and discussion of all the examinations and tests. The last section consists of the conclusions of this work.

\section{EXPERIMENTAL WORK}

\section{Materials}

Nickel (Ni) of high purity (99.2 wt.\%), titanium (Ti) of about (99.7 wt.\%), while silver (Ag) plates of high purity (99.9 wt.\%) used as an additive element at atomic percentages (1,2 and 3 at. \%) to prepare SMAs (Table I).

TABLE I: Different atomic percentages of each (Ni, Ti, $\mathrm{Ag})$.

\begin{tabular}{cccc}
\hline \hline Samples & Ni (at. \%) & Ti (at. \%) & Ag (at. \%) \\
\hline 1 & 55 & 45 & 0 \\
\hline 2 & 55 & 44 & 1 \\
\hline 3 & 55 & 43 & 3 \\
\hline 4 & 55 & 42 &
\end{tabular}

\section{Preparation of the Samples}

The chosen elements with the different atomic percentages, shown in Table I, were melted in (VAR) furnace type (ALD Vacuum Technologies AG) at $1350^{\circ} \mathrm{C}$ without graphite crucible. Figure (1.a) shows the VAR furnace using in this work to prepare shape memory alloys with the different atomic percentages of $\mathrm{Ag}$. In this work, there are two VAR methods used to manufacture shape memory alloys. The first method used a consumable electrode made of materials to be melted, while the second method used a non-consumable electrode. Raw metals (Ni, Ti and Ag) are installed on the copper mold and heated by irradiation using argon and the tungsten electrode, when the raw metals are melted down, their shape like the button because of the effect of surface tension. The melting process was followed by solidification (quenching in ice water), and then repeating the melting cycle 4 times to obtain the homogeneity in chemical composition, afterward, all the ingots were annealed at $660^{\circ} \mathrm{C}$ for $24 \mathrm{~h}$ by a programmable electric furnace. After that, the prepared ingots were sectioned by metals cutting machine. After cutting the samples, they were prepared for examinations by X-Ray Diffraction (XRD) analysis, Field Emission Scanning Electron Microscopy (FESEM), physical tests (Differential Scanning Calorimetry (DSC) test and Shape Memory Effect (SME) test) in order to know the starting and finishing of the phase transformations and the rate of shape recovery.

\section{Microstructural examinations}

\section{A. XRD}

XRD analysis was performed for all the samples before and after adding Ag element to define the phases as a result of the casting process. Also, it was used to study the effect of Ag atomic percentage on the resultant phases of the manufactured shape memory alloys. These phases are defined by lab (XRD-6000) System SHIMADZU Europe.

\section{B. FESEM}

This FESEM examination was carried out for all the samples before and after adding the silver element at different atomic percentages. Before testing, the samples must be ground by emery papers at 320,500 and $1000 \mu \mathrm{m}$ in grit size, and then polished by polishing cloth with chloride paste. After polishing, the samples etched using etching solution $(95 \mathrm{~mL} \mathrm{H} 2 \mathrm{O}+3.5 \mathrm{~mL} \mathrm{HNO} 3+1.5 \mathrm{~mL} \mathrm{HF})$ for $10 \mathrm{sec}$ [14]. After sample preparation, the samples coated with gold and palladium spray for 2 min and examined by FESEM type (cam scan Mv 2300).

\section{DSC}

The samples before and after adding Ag element were tested by Differential Scanning Calorimetry device (SETARAM, model 131 Evo) to estimate the starting and finishing 
transformation temperatures (As, Af, Ms, Mf). The weight of the sample of 5-10 $\mathrm{g}$ is placed in a small crucible made of aluminum and then heated in a DSC device at $450^{\circ} \mathrm{C}$ with a heating rate of about $10^{\circ} \mathrm{C} / \mathrm{min}$. As, Af, Ms and Mf were achieved at $-50^{\circ} \mathrm{C}-+230^{\circ} \mathrm{C}$.

\section{SME}

This test was carried out of the sample containing 3 at. $\%$ by pressing the sample about $(0.06 \%)$ from its original length Lo [21] using a compression test machine with $1 \mathrm{~mm} / \mathrm{min}$ displacement and then heating the sample in the air. Afterward, the shape memory effect would be calculated by the following formula [22].

$$
\mathrm{SME} \%=\frac{\mathrm{L}_{2}-\mathrm{L}_{1}}{\mathrm{~L}_{\mathrm{o}}-\mathrm{L}_{1}} \times 100
$$

Where:

Lo: Original length of sample (mm).

L1: Length of sample after pressing by $0.06 \%$.

L2: The return in length of sample after heating.

\section{RESULTS AND DISCUSSION}

\section{XRD analysis}

X-ray diffraction was performed by X-Ray diffractometer model (X.R.D-6000) SHIMADZU Europe with $\mathrm{CuK} \alpha$ radiation at the wavelength $(\lambda)=1.5405 \mathrm{~A}^{\circ}$ for all the samples of SMAs before and after adding Ag element.

Figure 1 shows XRD peaks of SMA NiTi (0 at. \% Ag) measured at room temperature at diffraction angles $(2 \theta)$ ranging about $35^{\circ}-76.5^{\circ}$. The strongest peaks for the Ni phase created at $(2 \theta)$ $44.5^{\circ}, 52^{\circ}$ and $76.5^{\circ}$ respectively for $(111),(200)$ and (200) planes. While Ti phase created at $(2 \theta)$ at $35^{\circ}-43.5^{\circ}$ and $63-71^{\circ}$ for the planes about (100), (002), (101), (200), (102) and (110) respectively. It must be emphasized that creating $\mathrm{Ti}_{2} \mathrm{Ni}$ (Austenite phase) at $(2 \theta)$ about $35.0^{\circ}-38.5^{\circ}$ and (110) plane.

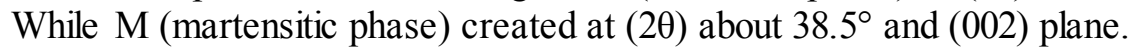

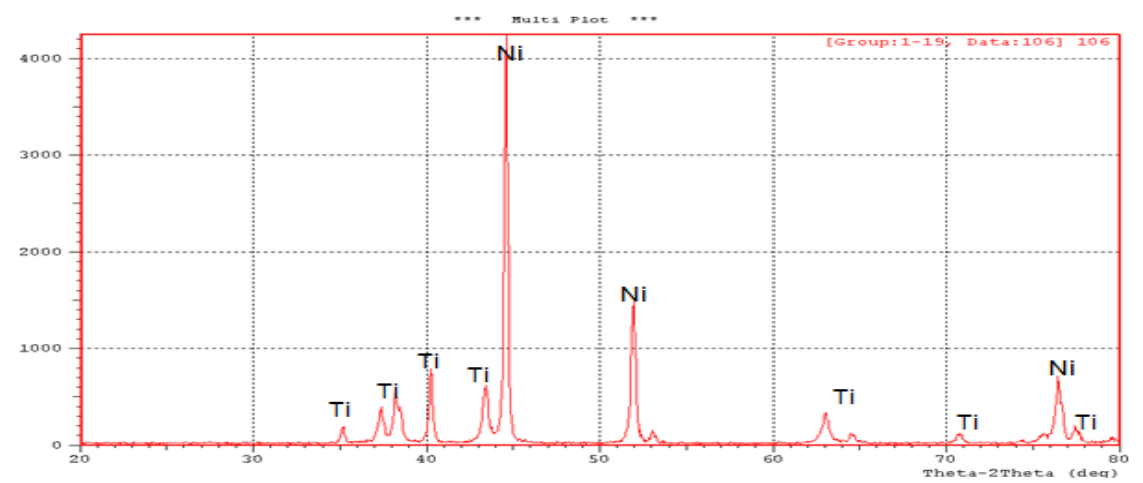

Figure 1: XRD peaks of 0 at. \% Ag element.

Figure 2 shows XRD peaks for SMA NiTi with ( 1 at. \% Ag). Here there are three main phases created; $\mathrm{Ni}$, Ti and $\mathrm{Ag}$ phases measured at room temperature which are occurred at $(2 \theta)$ ranging $35^{\circ}$ $77.6^{\circ}$. Ni phase is created at $(2 \theta)$ about $44.5^{\circ}, 52^{\circ}$ and $76.5^{\circ}$ for (111), (200) and (111) planes. While Ti phase is created at $(2 \theta)$ about $35^{\circ}, 40^{\circ}, 43.5^{\circ}, 53^{\circ}, 63^{\circ}$ and $71.0^{\circ}$ for $(100),(101),(200)$,

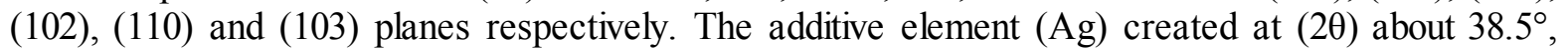
$64.6^{\circ}, 77.6^{\circ}$ for (111), (220) and (111) planes respectively. 


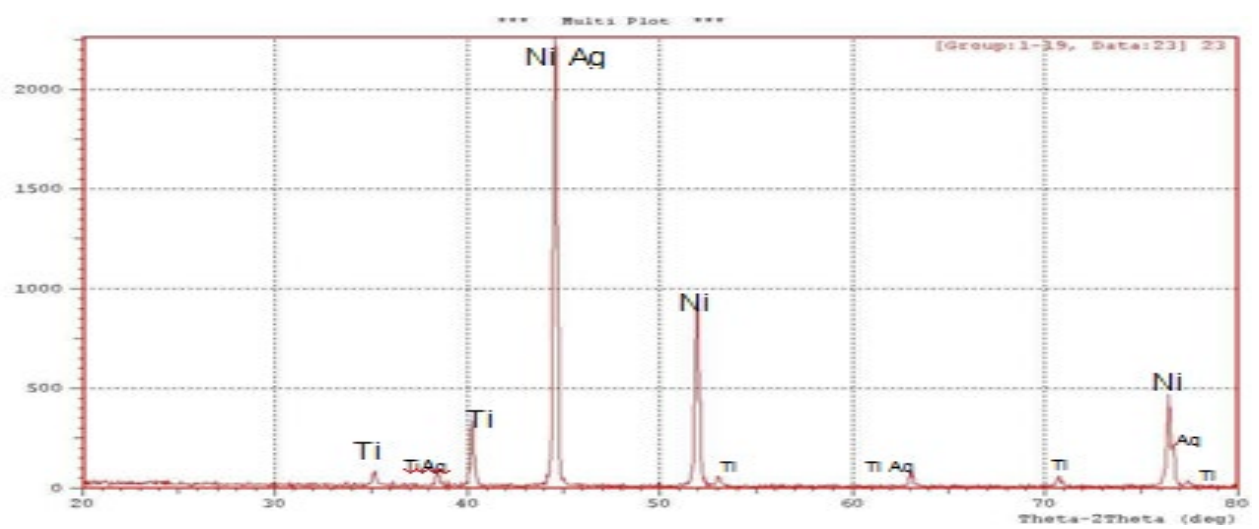

Figure 2: XRD peaks of 1 at. \% Ag element.

While Figure 3 shows the XRD peaks for SMAs NiTi with (2 at. \% Ag). There are three main phases created at $\mathrm{Ni}$, Ti and Ag phases, these phases occurred at $(2 \theta)$ ranging about $35^{\circ}-77.5^{\circ}$. Ni phase is created at $(2 \theta)$ about $44.5,52$ and 76.5 for (111), (200) and (111) planes respectively. While Ti phase is created at $(2 \theta)$ about $35^{\circ}, 38.5^{\circ}, 40.0^{\circ}, 53^{\circ}$ and $71.0^{\circ}$ for $(100),(002),(101),(102)$ and (103) planes respectively. Ag phase is created at $(2 \theta)$ about $37.5^{\circ}, 43.5^{\circ}, 44.5^{\circ}, 63^{\circ}$ and $77.5^{\circ}$ for (111), (200), (200), (220) and (111) planes respectively.

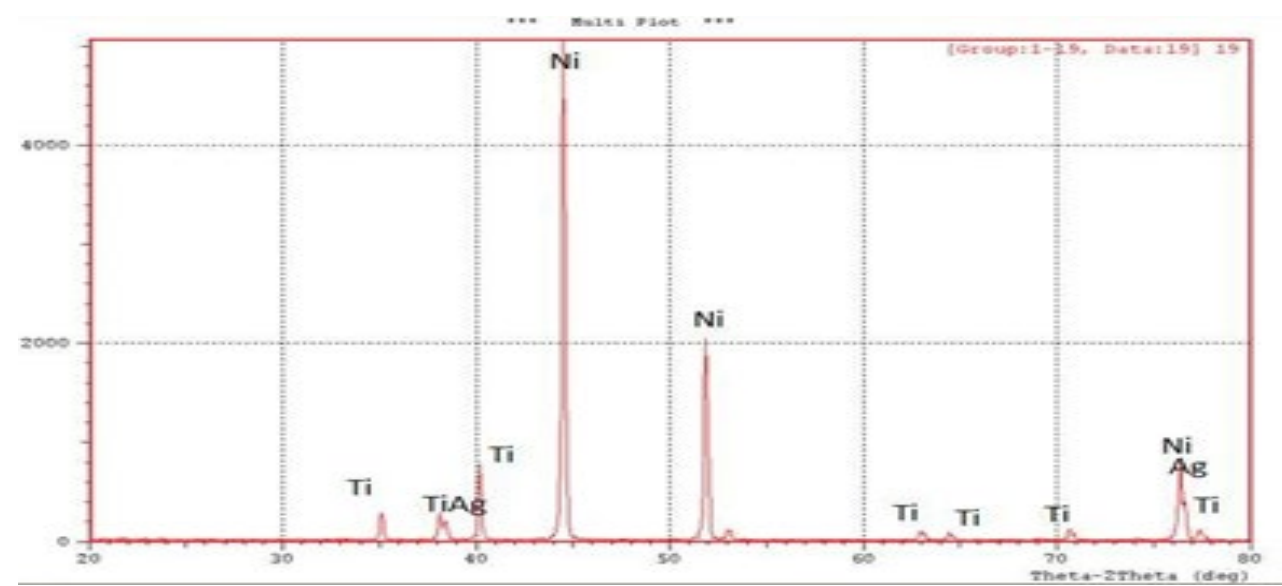

Figure 3: XRD peaks of 2 at. \% Ag element.

Finally, Figure 4 shows the XRD peaks for SMAs NiTi with ( 3 at. \% Ag). There are three main phases created as $\mathrm{Ni}$, Ti and Ag phases, these phases occurred at $(2 \theta)$ ranging about $35^{\circ}-77.5^{\circ}$. Ni phase is created at $(2 \theta)$ about $44.5^{\circ}$ and $76.5^{\circ}$ for (111), (111) planes respectively. While Ti phase is

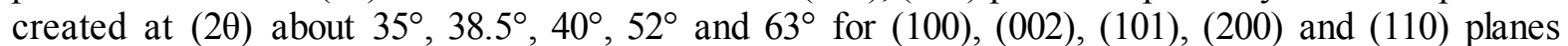
respectively. $\mathrm{Ag}$ phase is created at $(2 \theta)$ about $37.5^{\circ}, 43.5^{\circ}, 44.5^{\circ}, 53^{\circ}, 62^{\circ}, 71^{\circ}$ and $77.5^{\circ}$ for (111), (200), (200), (102), (220), (103) and (111) planes respectively.

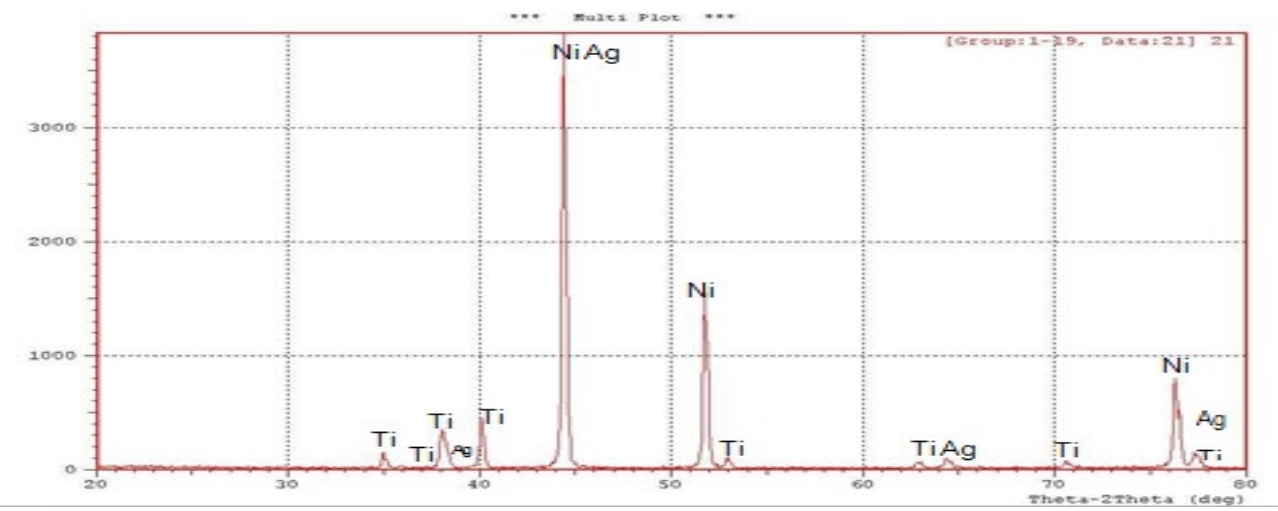

Figure 4: XRD peaks of 3 at. \% Ag element. 
From the results of XRD analysis, it is shown that increasing the atomic percentage of Ag leads to an increase in the peaks number of Ag phase

The results of XRD analysis revealed that, in heating, $\mathrm{Ti}_{2} \mathrm{Ni}$ (cubic austenite phase) is created at $\left(2 \theta=37^{\circ}\right)$ for $(110)$ plane. While, in cooling, there is Ti 002 phase (monoclinic martensite phase) will be created at $\left(2 \theta=38.5^{\circ}\right)$ for $(002)$ plane. Also, the results show a creation of undesirable phase $\mathrm{Ni}_{4} \mathrm{Ti}_{3}$ at $(2 \theta)$ about $44.5^{\circ}-52^{\circ}$ for (111) and (200) planes. This phase is created as a result of thermal transformation or the existence of some inclusions formed during melting. This is agreed with [23].

\section{FESEM}

Figure 5 shows the photomicrographs of SMAs before and after adding Ag element with the different atomic percentage to the NiTi-based alloy. The images reveal the martensite phase (Ti 002) and austenite phase $\left(\mathrm{Ti}_{2} \mathrm{Ni}\right)$ as a result of thermal transformation with a little number of inclusions which attributed to the impurities associated with the casting process, cutting, grinding and polishing of SMAs prepared in this work. These images agreed with XRD data.

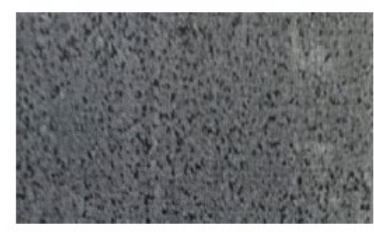

0 at. $\% \mathrm{Ag}$

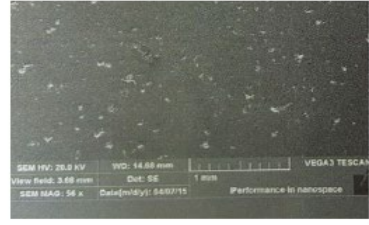

1 at. $\% \mathrm{Ag}$

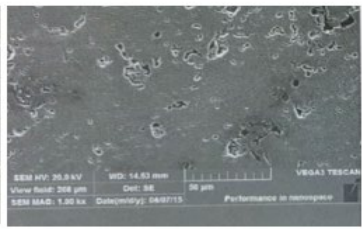

2 at. $\% \mathrm{Ag}$

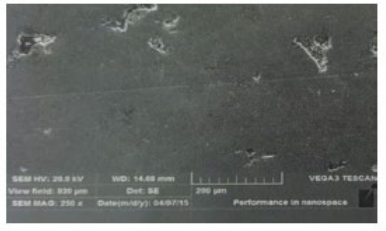

3 at. $\%$ Ag

Figure 5: Photomicrographs of the samples for different at. \% Ag.

\section{DSC}

Results of Differential Scanning Calorimeter (DSC) show starting and finishing transformation temperatures, for austenite and martensite phases. They are $A_{s}, A_{f}, M_{s}$, and $M_{f}$ respectively, as shown in Table II.

TABLE II: Phase transformation degrees (As, Af, Ms, Mf) for each alloy.

\begin{tabular}{ccccc}
\hline \hline Sample & \multicolumn{4}{c}{$\begin{array}{c}\text { Trans formation Temperature } \\
\left({ }^{\circ} \mathbf{C}\right)\end{array}$} \\
\cline { 2 - 5 } & $\boldsymbol{A} \boldsymbol{s}$ & $\boldsymbol{A}_{\boldsymbol{f}}$ & $\boldsymbol{M}_{\boldsymbol{s}}$ & $\boldsymbol{M}_{\boldsymbol{f}}$ \\
\hline Ni50Ti45Ag0 & 84.2 & 196.3 & 150 & 97.4 \\
\hline Ni50Ti44Ag1 & -49.2 & 58.1 & 149.15 & 104.9 \\
\hline Ni50Ti43Ag2 & 83.11 & 239.3 & 155.3 & 102.3 \\
\hline Ni50Ti42Ag3 & 138.8 & 179.3 & 163.01 & 117.0 \\
& & & & 5 \\
\hline
\end{tabular}

Figures 6, 7, 8 and 9 show the profile of the DSC test for all the samples of SMAs before and after adding the Ag element. These profiles containing two peaks created through heating and cooling which indicated thermal transformation from the austenite phase (B2) to the martensite phase (B19). There are two endothermal peaks formed through the heating process and two exothermal peaks created through the cooling process. This is returned to the formation of the $\mathrm{Ni}_{2} \mathrm{Ti}$ phase and fine precipitations which causes the large transformation of B2 to B19 (austenite to the martensite). This is agreed with [24]. 


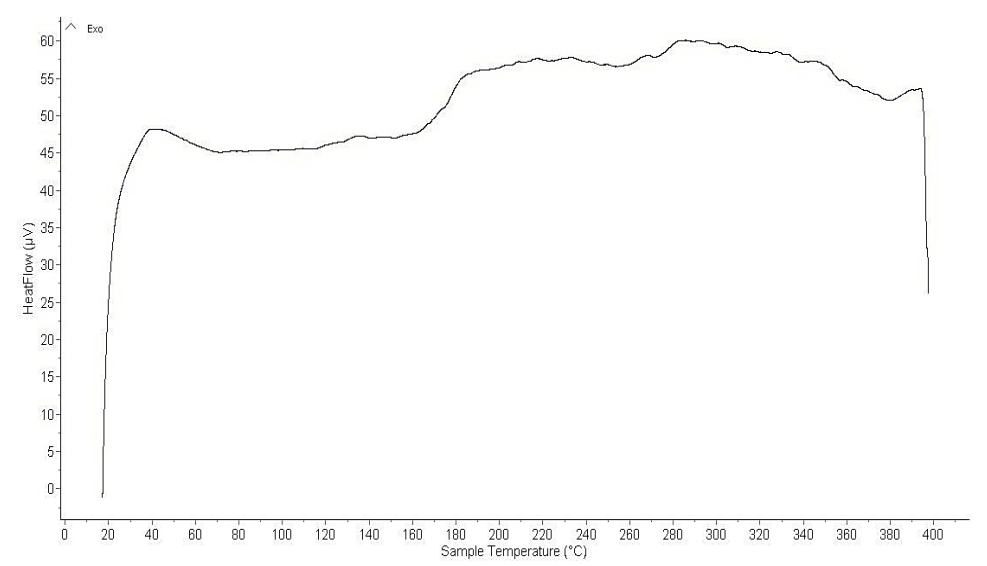

Figure 6: 0\% Ag element.

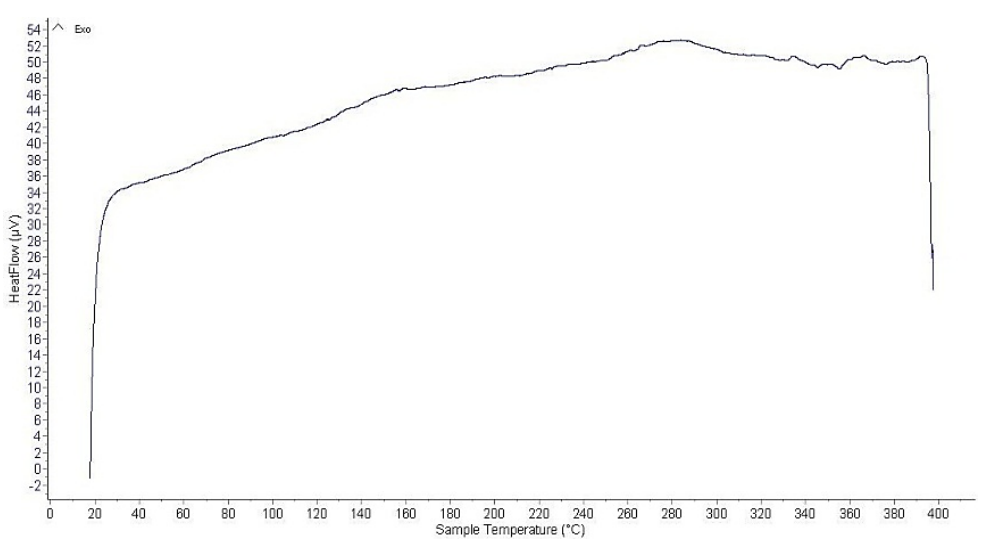

Figure 7: 1\% Ag element.

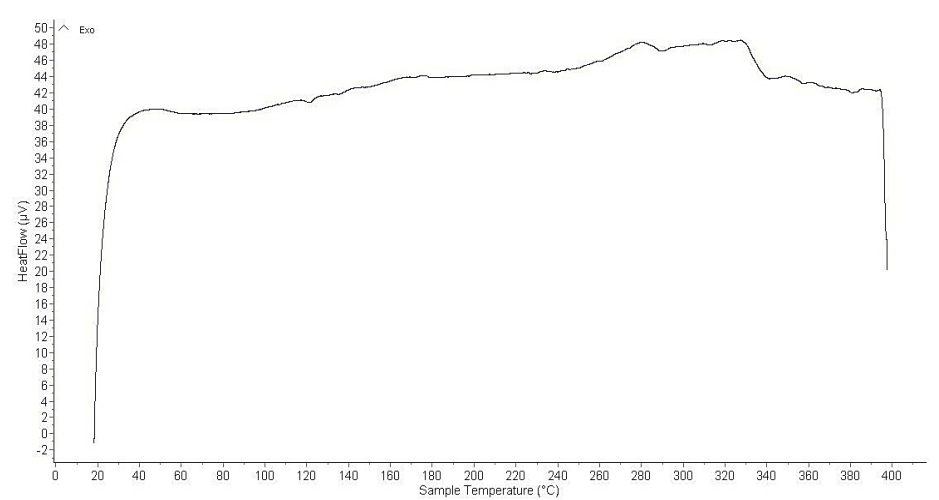

Figure 8: 2\% Ag element.

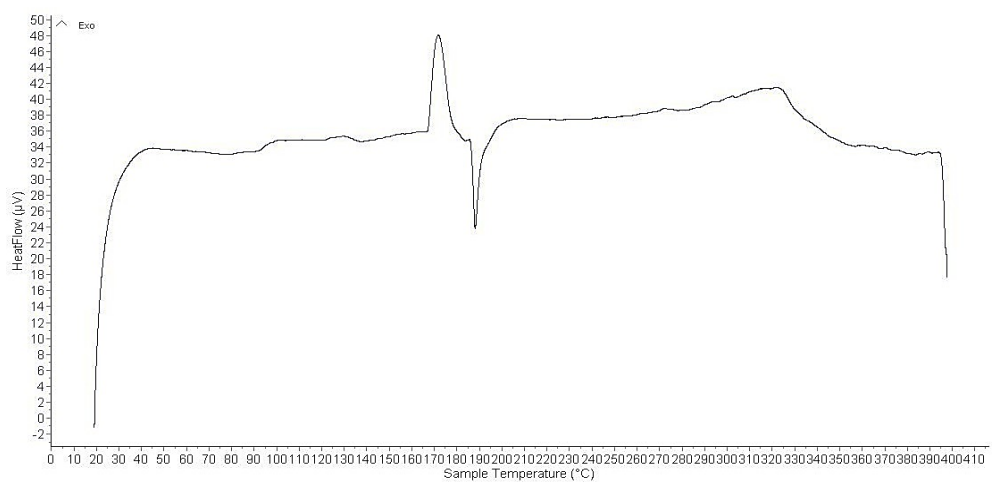

Figure 9: 3\% Ag element. 


\section{SME}

Shape Memory Effect (SME) is considered an important property of SMAs. As mentioned previously in experimental work and according to Eq. (1), the shape memory effect is about $89.99 \%$ which in turn is affected on physical properties. The improvement in most properties of SMAs manufactured with different atomic ratios is due to the purity of the materials used, the manufacturing method, uniform mixing, and the annealing process.

\section{CONCLUSIONS}

1) The results of the method used to manufacture shape memory alloys (SMAs) showed that the produced alloys are homogeneous, have uniform silver distribution, high purity alloys and have a shape memory effect of $(89.99 \%)$. This indicates the success of the manufacturing process by means of the casting process using a (VAR) furnace.

2) The examinations conducted on the four samples with different percentage of the silver element $(0,1,2$ and 3 at. \% Ag) by FESEM examination showed that the homogeneous silver distribution in NiTi matrix is due, in addition to the above parameters, to the emergence of martensite phase, austenite phase and some impurities as well.

3) The results of the XRD examination showed the emergence of martensite phase (Ti 002) with monoclinic structure upon cooling phase, Austenite phase $\left(\mathrm{Ti}_{2} \mathrm{Ni}\right)$ with cubic structure upon heating and undesirable phase $\left(\mathrm{Ni}_{4} \mathrm{Ti}_{3}\right)$ which is created as a result of the phase transformations well as some impurities resulting from the manufacturing process. This examination shows also the increasing appearance of peaks with the increase of the amount of silver.

4) The results of the DSC examination reveal the starting and finishing phase transformation temperatures (As, Af, Ms, Mf) for all alloys, which indicates the thermal transition from the austenite phase (B2) to the martensite phase (B19).

\section{Acknowledgment}

I extend my thanks, dedication and respect to the esteemed supervisors Assist. Prof. Dr. Khansaa Dawood Salman and Lec. Dr. Ahmed Abdulqader Hussein for their assistance in carrying out this research.

\section{References}

[1] M. H. Elahinia, M. Hashemi, M. Tabesh, S. B. Bhaduri, Manufacturing and processing of NiTi implants: A review, Prog. Mater. Sci., 57(2012)911-946. https://doi.org/10.1016/j.pmats ci.2011.11.001

[2] Y. Zheng, L. Cui, J. Schrooten, Temperature memory effect of a nickel-titanium shape memory alloy, Appl. Phys. Lett., 84 (2004) 31-33. https://doi.org/10.1063/1.1637958

[3] W. J. Buehler, J. V. Gilfrich, R. C. Wiley, Effect of low-temperature phase changes on the mechanical properties of alloys near composition TiNi, J. Appl. Phys., $34 \quad$ (1963) 1475-1477. https://doi.org/10.1063/1.1729603

[4] Álvares da Silva, Gilberto J. Otubo, Melting and Heat Treatment of an Ag-high Content NiTiAg Shape Memory Alloy: Microstructural and Thermal View, Conf. Paper., 69 (2014) 7507-7518. https://doi.org/10.5151/1516-392X-24657

[5] A. L. McKelvey, R. O. Ritchie, Fatigue-crack propagation in Nitinol, a shape-memory and superelastic endovascular stent material, J. Biomed. Mater. Res., 47(1999)301-308. https://doi.org/10.1002/(sici)10974636(19991205)47:3<301::aid-jbm3>3.0.co;2-h

[6] K. Otsuka, X. Ren, Martensitic transformations in nonferrous shape memory alloys, Mater. Sci. Eng., A. 273-275 (1999) 89-105. https://doi.org/10.1016/S0921-5093(99)00291-9

[7] X. L. Meng, Y. F. Zheng, Z. Wang, L.C. Zhao, Shape memory properties of the Ti36Ni49Hf15 high temperature shape memory alloy, Mater. Lett., 45 (2000) 128-132. https://doi.org/10.1016/S0167$\underline{577 X(00) 00091-4}$ 
[8] S. K. Wu, S. F. Hsieh, Martensitic transformation of a Ti-rich Ti40. 5Ni49. 5Zr10 shape memory alloy, J. Alloys. Compd., 297 (2000) 294-302. https://doi.org/10.1016/S0925-8388(99)00604-0

[9] T. Saburi, Ti-Ni shape memory alloys, Shape Memory Materials, Cambridge University, 1998.

[10] S. K. Bhaumik, Progress in the understanding of NiTi shape memory alloys, Trans. Indian. Inst. Met. 61 (2008) 435-445. https://doi.org/10.1007/s 12666-008-0076-4

[11] L. U. Peng, S. N. Wang, T.T. Zhao, L. Yan, Surface characteristics, corrosion behavior, and antibacterial property of Ag-implanted NiTi alloy, Rare. Metals., $32 \quad$ (2013) 113-121. https://doi. 10.1007/s 12598-013-0041-1

[12] R. Singhal, J. C. Pivin, R. Chandra, D. K. Avasthi, Ion irradiation studies of silver/amorphous carbon nanocomposite thin film, Surf. Coat. Technol., 229 (2013) 50-54. https://doi:10.1016/j.surfcoat.2012.05.131

[13] H. Matsumoto, Addition of an element to NiTi alloy by an electron-beam melting method, J. Mater. Sci. Lett., 10 (1991) 417-419. https://doi.org/10.1007/BF00728051

[14] K.T. Oh, U. H. Joo, G. H. Park, C. J. Hwang, K. N. Kim, Effect of silver addition on the properties of nickel-titanium alloys for dental application, J. of Biomedical Materials Research Part B: Applied Biomaterials: An Official Journal of the Society for Biomaterials, The Japanese Society for Biomaterials, and The Australian Society for Biomaterials and the Korean Society for Biomaterials. 76B (2006) 306-314. https://doi.org/10.1002/jbm.b.30369

[15] Y. F. Zheng, B. B. Zhang, B. L. Wang, Y.B. Wang, L. Li, Q. B. Yang, L. S. Cui, Introduction of antibacterial function into biomedical TiNi shape memory alloy by the addition of element Ag, Acta .Biomater., 7 (2011) 2758-2767. https://doi.org/10.1016/j.actbio.2011.02.010

[16] G. H. Á. Silva, J. Otubo, Designing NiTiAg Shape Memory Alloys by Vacuum Arc Remelting: First Practical Insights on Melting and Casting, Shap. Mem. Superelasticity., 4 (2018) 402-410. https://doi $\underline{10.1007 / \mathrm{s} 40830-018-0190-\mathrm{Z}}$

[17] R. Kocich, I. Szurman, M. Kursa, The methods of preparation of Ti-Ni-X alloys and their formin, Shape .Memory Alloys . Proc. Charact. Appl., (2013)28-35. http://dx.doi.org/\%2010.5772/50067

[18] S. X. Despin, N. Gregory, The unique properties, manufacturing processes and applications of near equatomic Ni-Ti alloys, Shap. Mem. Superelasticity. , 4 (2016) 402-410 .

[19] P. Olier, F. Barcelo, J. L. Bechade, J. C. Brachet, E. Lefevre, G. Guenin, Effects of impurities content (oxygen, carbon, nitrogen) on microstructure and phase transformation temperatures of near equiatomic TiNi shape memory alloys, J. Physi. IV., 7(1997) 143. http://dx.doi.org/10.1051/jp4:1997522

[20] J. Otubo, O. D. Rigo, C. D. M. Neto, M. J. Kaufman, P. R. Mei, Low carbon content NiTi shape memory alloy produced by electron beam melting, Mater. Res., 7 (2004) 263-267. https://dx.doi.org/10.1590/S151614392004000200008

[21] Marek Novoltny, Shape memory alloys (SMAs), Novotny@ac.tut.fi, 2008.

[22] J.F .Wan, X .Huang, S.P .Chen, T.Y.Hsu, Effect of nitrogen addition on shape memory characteristics of Fe-Mn-Si-Cr alloy, Mater. Trans., 43(2002) 920-925. https://dx.doi.org/10.2320/matertrans.43.920

[23] Al-Hasani Emad Saadi, Preparation and corrosion behavior of Ni-Ti shape memory alloys, PhD. Thesis, University of Technology, Baghdad, Iraq, 2007.

[24] Y. Liu, M. Blane, G. Tan, J. I. Kim, S. Miyazaki, Effect of ageing on the transformation behavior of Ti49.5 at.\% Ni, Mate. Sci. Eng. A., 438-440 (2006)617-621. https://doi.org/10.1016/i.msea.2006.02.165 